\title{
Early E1A Protein
}

National Cancer Institute

\section{Source}

National Cancer Institute. Early E1A Protein. NCI Thesaurus. Code C17473.

Early E1A protein is encoded by the adenovirus E1A gene. This protein is involved in inducing infected cells to enter the cell cycle and promoting replication of the viral genome. 